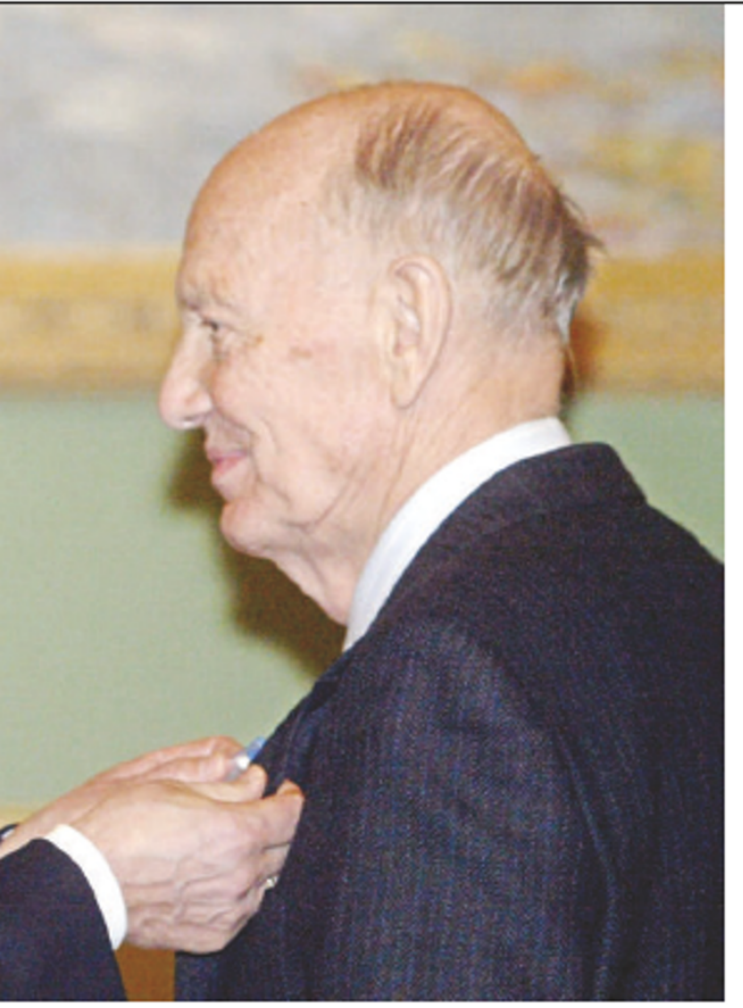

"Nothing will change in Ukrainian science as long as this system exists."

Ukrainian scientists are eligible for EU research money thanks to a 2002 association agreement with the European Commission's framework programme for research. But so far, only seven out of thousands of EU-funded projects include Ukrainian participants, says Vadym Yashenkov, deputy director of Ukraine’s National Information Point for EU research.

According to Yashenkov, this is partly because of the general weakness of Ukrainian science and industry, and the complicated application procedures that put off many scientists.

But participation is also hindered because the academy fails to provide and disseminate relevant documents and information, says Oleh Napov, a science attaché at the Ukrainian mission to the EU in Brussels, Belgium. For example, Napov has submitted a proposal for scientific reform to the Ukrainian research ministry. He says that when he asked the academy to outline its scientific priorities, he received only a list of the names and titles of all current academicians, and a letter stating that the academicians themselves were the academy's priorities.

${ }^{\alpha}$ Maybe they have not asked us in a proper way, counters Yaroslav Yatskiv, director of the Main Astronomical Observatory in Kiev, and a member of the academy's presidium. The president, Paton, had not responded to queries when Nature went to press.
Yatskiv says he is aware that corruption is a widespread problem within the academy. "It is true, unfortunately, that funding is not based on scientific merit," he says. But he adds that efforts to evaluate and possibly transform the academy are being considered.

\section{Brain drain}

Yatskiv has recently proposed the creation of a National Science Foundation that, like its US counterpart, would fund research on the sole basis of excellence judged by peer review. But Paton last year told a presidium meeting that the future role of the academy should be similar to that of the Siberian branch of the Russian Academy of Sciences, another relic of the Soviet science complex. "I don't think this is a good idea," says Yatskiv.

Resistance to the academy's backward-looking plans is growing, both inside and outside Ukraine. A 13-strong group of Ukrainian scientists, led by Boyarski, has suggested to the country's science ministry a detailed concept of domestic reform, including rigorous evaluation of all academy institutes, the creation of an international institute of advanced study in Kiev and of a number of centres of excellence supported by the EU.

${ }^{\alpha}$ Things back home really need to improve substantially," says Alexej Verkhratsky, a Ukrainian-born neurophysiologist at the University of Manchester and a member of Boyarski's group. "If they don't, our best young people will soon have left for good. A considerable number of Ukrainian scientists working abroad (myself included) would come back if things were reorganized."

${ }^{\alpha}$ We have the same potential, scientifically and politically, as Poland or Hungary to become a genuine part of Europe," adds Oleg Krishtal, deputy director of the academy's Bogomoletz institute of physiology in Kiev. ${ }^{\alpha}$ What we need is proper political stimulus. Clearly, the academy cannot repair itself as long as the old guard is keeping all the key positions."

Christian Patermann, director for biotechnology, agriculture and food at the European commission's directorate general for research in Brussels, led an EU delegation to Ukraine last month. He says that the country's scientific potential in areas such as materials sciences, energy, space and organic farming is impressive and deserves European support. Patermannn is optimistic that the academy will not ultimately stand in the way of reform. "The Czech Republic, Hungary and the Baltic countries have all managed to reform their academies of science; sooner or later this will also happen in Ukraine."

Seealso page 128.

Quirin Schiermeier
ON THE RECORD

"Mars is hard, and Mars is unpredictable. Mars doesn't treat you very well."

NASA's Jim Graf crosses his fingers for the Mars Reconnaissance Orbiter spacecraft, due to arrive at the red planet on 10 March.

\section{'Libertines, both male and female, have always been around in math and physics."}

Science writer Jennifer Ouellette ponders whether physicists are really having more sex these days.

Sources: Washington Post, Seed

\section{SCORECARD}

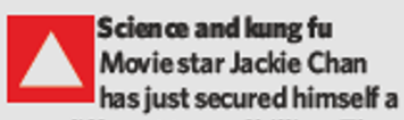
very different type of billing. The Australian NationalUniversity is naming a new science centre after the action hero as a vote of thanks for his recent donation.

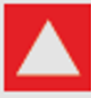

Waterfowl Researchers in Canada have come up with a way tostop wading birds landing on oil fields in Alberta. As the birds fly in, radar picks them up and triggers a deterrent noise.

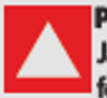

Perfume

Japanese scientistshave found an unusual source of vanillin, the aromatic component of vanilla usedas a fragrance. The sweet smell can, apparently, be extracted from cow dung.

\section{NUMBER CRUNCH}

A study by the US Centers for Disease Control and Prevention suggests that moving to the United States, especially if you are hispanic, might be bad for yourhealth.

$16 \%$ of Hispanicimmigrants living in the United States for five years or less are obese.

$13 \%$ of the same group have high blood pressure.

$22 \%$ of Hispanic immigrants living in the UnitedStates for more than five years are obese.

$20 \%$ of the same group have high blood pressure. 